\title{
The Effect of Using Google Translator Website on Understanding a Short Story
}

\author{
ALAA SALMAN M. ALSHAKHS \\ General Department and English Center, AL-Hassa Technical College, PO box 804 AL-Hassa 31982 Saudi \\ Arabia
}

\begin{abstract}
Translation has historically been performed by traditional ways like paper dictionary or by asking expert bilinguals who is equipped by strong knowledge. This way of translation was further driven by the digital revolution in the $90 \mathrm{~s}$ where a huge need of interpreting text from source language and into target language. Twenty years on, translation means continue to flourish, even tending towards machine translation. Consequently, this technology became a part of everyone's life. This paper is to highlight the advantage of using Google translation website on understanding a short text by secondary school students.
\end{abstract}

Keywords: Google Translate, ESP students, machine translation, translation utilization.

DOI: $10.7176 / \mathrm{JEP} / 10-18-14$

Publication date: June $30^{\text {th }} 2019$

\section{Introduction}

Using technology, specifically smartphones has affected the behavior of people and change is touched by educators more keenly than most. Like all the studying areas, learning English has been affected by this technology as much as the learners obliged to be connected to the screens of their smartphones.

Understanding English for ESP students is not an easy mission. Usually, they struggle to guess the meaning of a single word despite the context. Here where they need an effective tool to help in the shortest time. The development of gadgets utilized the electronic dictionaries, spelling checkers, grammar checkers and dictionaries on CDs during the past decade which made them more accessible to many students.

This paper discussing the effect of using machine translation in the form of Google website as an assistant tool to enhance students' understanding of an English text consists of 113 words in a story context. It is also highlighting the dynamic key rule of understanding the meaning of the words of the target language.

\section{Review of Literature}

Alshiekh (2011) explored the translation process which is provided by Google Translate website without ignoring the drawbacks of its use as a machine translator over and above the prospect of humanizing the system used. The frame of this research is limited to translation from Arabic into English and English into Arabic. The data shown in this study is gathered from translation assignment by Zarqa University during Semester 2010 under the guidance of the Research Center to learners in the Department of English and Translation in their Research Writing Course. The Author suggests that the use of grammatical structures is English must be more focused: otherwise, Google translator website appears to operate primarily as a bilingual dictionary rather than a proper MT program.

Another study carried by Al-Jarf (2001) on 178 student majoring in translation at the college of Language and Translation where 10 translation and interpreting instructions were surveyed. This search found $45 \%$ of the students use electronic dictionaries and $99 \%$ out of $45 \%$ use a general English-Arabic while on the other hand $68 \%$ use an Arabic-English electronic dictionary and $27 \%$ out of $45 \%$ use English-English electronic dictionary while only $2 \%$ of them use a specialized electronic dictionary. The research also found $70 \%$ of the translation instructors do not allow students to use an electronic dictionary in class or test sessions.

Dr. Ignacio Gracia (2009) who is a Senior Lecturer at the School of Humanities and Languages, discussed the history and the stages of the revolution of translation. He insisted that this professionalization was driven by the digital revolution in the 90s. However, by focusing on the segment, the same technological procedures that empower the professional translator also signaled a return to the bottom-up strategy.

\section{Research hypothesis}

Using Google translator website has a positive effect on understanding a short story consists of 100 words.

\section{Classroom Context}

The project was created for the freshmen in Al Hofuf, Saudi Arabia, specifically Al Hassa Technical College.

Participants: 30 students aged 17-20 years old. They divided into two groups in this experiment: control group, experiment group. Participants were randomly assigned to two groups. All participants' English background is EFL with relatively weak proficiency. 
Materials: Short story consists of 100 words beginner-level, namely (The Yellow Pencil). Internet connection, tablet, smartphones, Google translation website.

\section{The Experiment}

As part of regular English class session, the research experiment took place. The class divided into two groups: The experiment group here is allowed to use their smartphones/ tablets to browse the Google translation website. The other group is the control group where students were not allowed to use their smartphones at all. Both groups given the same reading text (The Yellow Pencil). The time was limited to 25 minutes to finish reading. Next, they were given five comprehension questions about the text. Due to their proficiency, these questions were written in their native language (Arabic).

\section{Findings}

\subsection{Communicative Theory}

The Communicative approach is one of the six modern theories for translation. This view is called interpretive. Investigators like D. Seleskovitch and M. Leader created what they called "sense theory," based primarily on a conference interpretation experience. Significance must be comprehension according to this view. That's why it's always easier to understand.

\subsection{Results and Discussions}

Five comprehension questions were given after reading a short story consists of 100 words designed for beginners level. The grade was out of 10 . The was limited to 25 minutes with possibility to turn the paper any time as long as it is within the 25 minutes. Then, the average grade calculated for both groups as shown in table 1 and table 2 below.

Among 30 freshmen students who participated in the study, 50\% of them (the experiment group) allowed to use Google Translator on their gadgets. However, many of the experiment group participants comment that they need more time to finish reading as they are trying to translate.

Table. 1 shows that the average score is 8.7 out of 10 and 3 students got 10 out of 10 and the minimum grade for this group was 6 out of 10 where only one student collected it.

However, the other $50 \%$ of the participant who were 15 students (the control group) did not allow to use any electronic translator where they mostly translate the sentences based on their bank of memorized words or the help of understanding the context. It worth to be noted that they finished faster than the other group but with vast lower grades results. Table. 2 shows that the average score is 3.86 out of 10 . The highest grade is 5 and the lowest is 2 .

Table: 1 The experiment group results

\begin{tabular}{|c|c|}
\hline \multicolumn{2}{|c|}{ The Experiment Group Results } \\
\hline Number of Students & The Score \\
\hline 3 & 10 \\
\hline 8 & 9 \\
\hline 2 & 8 \\
\hline 1 & 7 \\
\hline 1 & 6 \\
\hline
\end{tabular}

Table: 2 The control group results

\begin{tabular}{|c|c|}
\hline \multicolumn{2}{|c|}{ The Control Group Results } \\
\hline Number of Students & The Score \\
\hline 6 & 5 \\
\hline 3 & 4 \\
\hline 2 & 3 \\
\hline 5 & 2 \\
\hline
\end{tabular}

After a careful observation of the grades, basing on the results from table. 1 to table. 2 a major increase in the results of the students who used Google translator up to $100 \%$ in the performance of the students which confirms the theory of Seleskovitch and M. Leaderer. 


\section{Conclusion}

This research came to find about the effect of using Google Translator Website standing on the Communicative Theory. The results confirm that using a translator which could be Google translator, helps EFL learners to understand the meaning and consequently increase the ability to deal and interact with the text which is proven by answering the comprehension question up to $100 \%$ higher than those who did not use any translator.

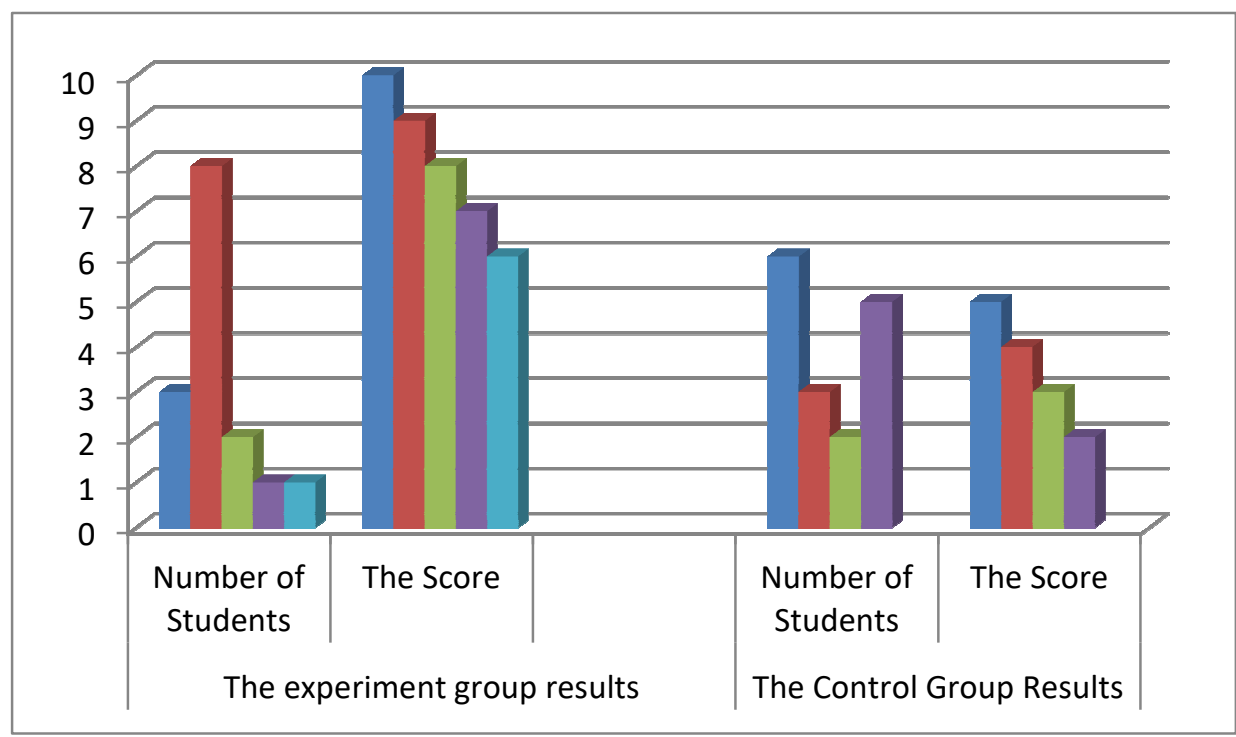

Figure 1. The Experiment Group Results vs The Control Group Results

\section{Recommendations}

According to the results, researchers could be encouraged to further exploration taking the findings into the next level in a hope this research stimulates researchers in this field.

\section{References}

Fragoso, Victor, et al. "TranslatAR: A Mobile Augmented Reality Translator." TranslatAR: A Mobile Augmented Reality Translator - IEEE Conference Publication, IEEE, 10 Feb. 2011, ieeexplore.ieee.org/abstract/document/5711545.

"6 Contemporary Theories to Translation." Cultures Connection, 31 Oct. 2016, culturesconnection.com/6contemporary-theories-to-translation/.

Al-Jarf, Reima Saad. "Electronic Dictionaries in Translation Classrooms in Saudi Arabia." Linguistica Communicatio, vol. 10, no. 127, ser. 134, 12 Nov. 2001, pp. 1-10. 134.

Ignacio Garcia. "Beyond Translation Memory: Computers and the Professional Translator." The Journal of Specialised Translation, 12 July 2009, pp. 199-2014.

Elshiekh, Ahmed Abdel Azim. "Google Translate Service: Transfer of Meaning, Distortion or Simply a New Creation? An Investigation into the Translation Process \& Problems at Google." English Language and Literature Studies, vol. 2, no. 1, 2012, pp. 56-68., doi:10.5539/ells.v2n1p56.

Jungwha, Choi. "The Interpretive Theory of Translation and Its Current Applications ." JAIS, 3 Dec. 2003 , pp. 1-15., jaits.jpn.org/home/kaishi2003/pdf/01-choi_final_.pdf.

\section{Appendix A}

\section{The Yellow Pencil}

David lost his yellow pencil. He could not find it. "Where is my yellow pencil?" he asked his sister. His sister did not know. "I don't know where your pencil is," she said. David thought about it. He thought and thought. He used his yellow pencil before lunch. He used it to write a note to his teacher. The note said, "Dear Teacher, Thank you for helping me. David." He put the note in an envelope. Where was the envelope? He looked in the kitchen. He looked in the kitchen counter. He found the envelope. It was next to the toaster. He found the pencil. It was under the toaster. 